\title{
Inhibitory effect of brassinin on TNF- $\alpha$-induced vascular inflammation in human umbilical vein endothelial cells
}

\author{
BYUNG HYUK HAN ${ }^{1,2}$, JUNG JOO YOON ${ }^{1,2}$, EUN SIK CHOI ${ }^{1,2}$, DA HYE JEONG ${ }^{1,2}$, YUN JUNG LEE ${ }^{1,2}$, \\ DAE GILL KANG ${ }^{1,2}$ and HO SUB LEE ${ }^{1,2}$
}

\author{
${ }^{1}$ College of Oriental Medicine and Professional Graduate School of Oriental Medicine; ${ }^{2}$ Hanbang Body Fluid Research Center, \\ Wonkwang University, Iksan, Jeonbuk 54538, Republic of Korea
}

Received September 5, 2016; Accepted April 27, 2017

DOI: $10.3892 / \mathrm{mmr} .2017 .7406$

\begin{abstract}
Brassinin, a phytoalexin firstly identified as a constituent of Chinese cabbage, has been demonstrated to exhibit antiproliferative effects on various cancer cell lines, by reducing reactive oxygen species (ROS) production via regulation of the antioxidant pathway. The present study aimed to explore the protective effects of brassinin in TNF- $\alpha$-induced vascular inflammation in human umbilical vein endothelial cells (HUVECs). Pretreatment with brassinin significantly inhibited adhesion of U937 cells to TNF- $\alpha$-induced HUVECs in a dose-dependent manner. Brassinin treatment decreased the expression levels of cell adhesion molecules, including intracellular adhesion molecule-1 (ICAM-1), vascular cell adhesion molecule-1 (VCAM-1), and endothelial-selectin (E-selectin) following stimulation with TNF- $\alpha$ in HUVECs. In addition, pretreatment with brassinin decreased the protein expression levels of nuclear factor (NF)- $\kappa$ B p65 in the nucleus, suggesting that brassinin inhibited NF- $\kappa \mathrm{B}$ p 65 nuclear translocation. Brassinin treatment also markedly decreased the mRNA expression levels of interleukin- 8 in a dose-dependent manner. Finally, brassinin pretreatment significantly decreased TNF- $\alpha$-induced intracellular reactive oxygen species (ROS) production in HUVECs compared with control. The present results therefore suggest that brassinin may serve as a potential therapeutic agent for atherosclerosis.
\end{abstract}

\section{Introduction}

Vascular inflammation is an important process leading to endothelium disorders and atherosclerosis. The activation

Correspondence to: Professor Ho Sub Lee or Dr Dae Gill Kang, College of Oriental Medicine and Professional Graduate School of Oriental Medicine, Wonkwang University, 460 Iksandae Road, Iksan, Jeonbuk 54538, Republic of Korea

E-mail: host@wku.ac.kr

E-mail: dgkang@wku.ac.kr

Key words: brassinin, human umbilical vein endothelial cells, tumor necrosis factor- $\alpha$, vascular inflammation, atherosclerosis of the endothelium at inflammation sites allows leukocytes to adhere to the vascular endothelial layer. This then results in increased leukocyte infiltration into the vessel wall and leukocyte differentiation into macrophages, a process that is an important early event of endothelial dysfunction and tissue injury (1). The production of cytokines is another early event of atherosclerosis, due predominantly to the large number of macrophages resident in atherosclerotic plaques (2).

Tumor necrosis factor (TNF)- $\alpha$, an endothelial cell-derived cytokine, exists in atherosclerotic lesions and can increase the expression of cell adhesion molecules, including vascular cell adhesion molecule-1 (VCAM-1), intracellular adhesion molecule-1 (ICAM-1), and endothelial-selectin (E-selectin), which then contribute to the inflammatory process $(3,4)$. Interleukin (IL)- 8 is found in human atheroma, and mice lacking its receptors are less sensitive to atherosclerosis and have fewer monocytes in vascular lesions. In addition, IL-8 serves a critical role in the firm adhesion of monocytes to vascular endothelium, revealing an unexpected role for this chemokine in monocyte recruitment (5). Nuclear factor (NF)- $\kappa B$ is a major transcription factor in vascular inflammation. TNF- $\alpha$ is tightly regulated by transcriptional activation of NF- $\mathrm{\kappa B}(6)$ and NF- $\kappa \mathrm{B}$ serves a key role in the inflammatory process by increasing the expression of many inflammatory mediators, mediated by degradation of its inhibitor of $\kappa \mathrm{B}$ (IкB) (7). In addition, NF- $\kappa B$ regulates transcriptional activation of important pro-inflammatory and cell adhesion molecules (8). The mechanisms involved in NF- $\mathrm{\kappa B}$ activation include the increase of intracellular levels of reactive oxygen species (ROS), which results from the increase in pro-inflammatory cytokines $(9,10)$. Therefore, regulation of the ROS/NF- $\kappa$ B pathway, as a critical key mediator of inflammatory responses, may be a useful strategy towards the treatment of vascular diseases, such as atherosclerosis (11).

Brassinin [3-(S-methyldithiocarbamoyl) aminomethyl indole; chemical structure illustrated in Fig. 1], is a type of indole compound derived from cruciferous vegetables. Brassinin has demonstrated anticancer effects in cells and animals (12). It has been reported that brassinin can affect the effectiveness of chemotherapy against established tumors in an autochthonous mouse model of breast cancer (13). Brassinin has also been reported to have antiproliferative effects in cancer cells by inhibiting the production of oxidative stress 
and ROS (14). However, no report exists to date regarding the role of brassinin in vascular endothelial cells. The present study was designed to investigate the effect of brassinin on TNF- $\alpha$-induced vascular inflammation in human umbilical vein endothelial cells (HUVECs).

\section{Materials and methods}

Chemicals and materials. TNF- $\alpha$, EDTA, antibiotic-antimycotic solutions and fetal bovine serum (FBS) were purchased from Invitrogen (Thermo Fisher Scientific, Inc., Waltham, MA, USA). Dimethyl sulfoxide (DMSO) was purchased from Amresco, LLC (Solon, OH, USA). Brassinin, and primary antibodies targeting VCAM-1 (sc-13160), ICAM-1 (sc-8439), E-selectin (sc-14011), IкB- $\alpha$ (sc-203), p-IкB- $\alpha$ (sc-8404), $\mathrm{NF}-\kappa \mathrm{B}(\mathrm{sc}-8008)$ and $\beta$-actin $(\mathrm{sc}-4778)$ were purchased from Santa Cruz Biotechnology, Inc. (Dallas, TX, USA) and diluted at 1/1,000 with TBS. Horseradish peroxidase (HRP)-conjugated secondary antibodies [goat anti-mouse-IgG (A90-1169), donkey anti-goat-IgG (A50-1019) and goat anti-rabbit-IgG (ADI-SAB-300-J)] were obtained from Bethyl Laboratories, Inc. (Montgomery, TX, USA) and Enzo Life Sciences, Inc. (Farmingdale, NY, USA) and diluted at 1/5,000. $\mathrm{N}$-acetylcysteine (NAC) was purchased from Sigma-Aldrich (Merck KGaA, Darmstadt, Germany). All other reagents used in the present study were of the highest purity commercially available.

Cell culture. HUVECs and U937 monocyte cells were obtained from the American Type Culture Collection (Manassas, VA, USA). Cells were maintained at $5 \times 10^{5}$ cells $/ \mathrm{ml}$ in RPMI-1640 medium D (Gibco; Thermo Fisher Scientific, Inc.) supplemented with $10 \%$ heat-inactivated FBS and $100 \mathrm{U} / \mathrm{ml}$ penicillin $\mathrm{G}$ and incubated at $37^{\circ} \mathrm{C}$ in a humidified atmosphere containing $5 \% \mathrm{CO}_{2}$ and $95 \%$ air.

Monocyte-HUVEC adhesion assay. HUVECs were cultured to confluence in 6-well culture plates, pretreated with brassinin for $30 \mathrm{~min}$, and then stimulated with TNF- $\alpha$ for $6 \mathrm{~h}$. U937 cells were labeled with $10 \mu \mathrm{M}$ BCECF-AM (Sigma-Aldrich; Merck $\mathrm{KGaA}$ ) for $1 \mathrm{~h}$ at $37^{\circ} \mathrm{C}$ and washed twice with growth medium. Labeled U937 cells $\left(2.5 \times 10^{5}\right)$ were seeded onto the HUVECs, and further incubated for $1 \mathrm{~h}$. The non-adherent U937 cells were removed from the plate by washing with PBS, and the U937 cells bound to HUVECs were measured by fluorescence microscopy, and then lysed with $50 \mathrm{mM}$ Tris-HCI pH 8.0, containing $0.1 \%$ SDS. Fluorescence intensity was measured using a spectrofluorometer (Infinite F200 Pro; Tecan Group Ltd., Mannedorf, Switzerland) at excitation and emission wavelengths of 485 and $535 \mathrm{~nm}$, respectively. The adhesion data were represented in terms of percent change compared with the control group.

Western blot analysis. HUVECs were washed twice with ice-cold PBS and lysed with buffer (radioimmunoprecipitation assay lysis buffer, WSE-7420, ATTO Corporation, Tokyo, Japan). Protein content was determined using the Bradford method. Cell homogenates (40 $\mu \mathrm{g}$ total protein) were separated on $10 \%$ SDS-polyacrylamide gel electrophoresis and transferred to nitrocellulose membranes. Blots were then

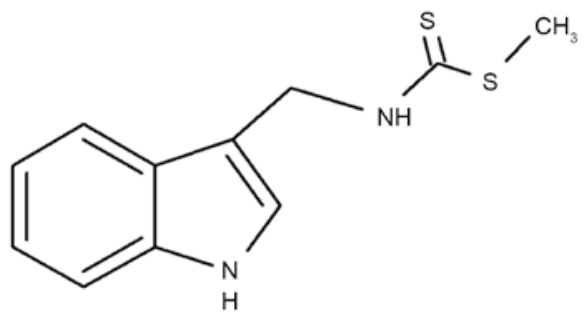

Figure 1. Brassinin chemical structure.

washed with TBST [10 mM Tris-HCl (pH 7.6), $150 \mathrm{mM}$ $\mathrm{NaCl}, 0.05 \%$ Tween-20], blocked with $5 \%$ BSA in TBS for $1 \mathrm{~h}$ in room temperature and incubated with the appropriate primary antibody in $4^{\circ} \mathrm{C}$ for $\sim 8 \mathrm{~h}$. Then the membrane was washed, and primary antibodies were detected with goat anti-rabbit-immunoglobulin (Ig) $\mathrm{G}$ or anti-mouse-IgG conjugated to HRP for $2 \mathrm{~h}$ at room temperature, and the bands were visualized with enhanced chemiluminescence (Atto Corporation, Tokyo, Japan). Protein expression levels were determined by analyzing the signals on a ChemiDoc imaging system (Bio-Rad Laboratories, Inc., Hercules, CA, USA). For quantitative analysis, the average score of each band was calculated using ImageJ (National Institutes of Health, Bethesda, MD, USA) (15).

Cell ELISA. ELISA was used to determine the levels of ICAM-1, VCAM-1 and E-selectin expression on the cell surface, as previously described with minor modifications. HUVECs were seeded on 96-well plates at a concentration of $1 \times 10^{5}$ cells/well. Briefly, HUVECs were pretreated with or without brassinin for $30 \mathrm{~min}$, which was followed by TNF- $\alpha$ treatment for $6 \mathrm{~h}$ at $37^{\circ} \mathrm{C}$. Following treatments, the cells were fixed with $1 \%$ paraformaldehyde and exposed to mouse anti-human ICAM-1, VCAM-1 or E-selectin antibody at 1:1,000 dilution in PBS containing 1\% skim milk for $2 \mathrm{~h}$ at room temperature. The cells were washed and incubated with a HRP-conjugated secondary antibody. The expression of ICAM-1, VCAM-1, or E-selectin was quantified by adding a peroxidase substrate solution and measuring the absorbance of each well at $490 \mathrm{~nm}$ using a microplate reader (Molecular Devices, LLC, Sunnyvale, CA, USA).

RNA extraction and reverse transcription-polymerase chain reaction $(R T-P C R)$. Total mRNA was isolated from cultured HUVECs using a commercially available kit (RNeasy Mini kit; Qiagen, Inc., Valencia, CA, USA). In the first step, cDNA was prepared from $500 \mathrm{ng}$ mRNA by reverse transcription in a final volume of $20 \mu \mathrm{l}$ in cDNA synthesis kit (M-MIV cDNA Synthesis kit; EZ006S; Enzynomics, Co., Ltd., Daejeon, Korea). The reactions were incubated at $37^{\circ} \mathrm{C}$ for $60 \mathrm{~min}, 94^{\circ} \mathrm{C}$ for $5 \mathrm{~min}$, and then cDNA was used or immediately stored at $-20^{\circ} \mathrm{C}$. Template cDNA and $50 \mathrm{nM}$ primers were added in PCR premix (Rb Taq Fast qPCR 2X Premix; RT540S; Enzynomics, Co., Ltd.) according to the manufacturer's protocol. Primer sequences were as follows: IL-8 forward, 5'-ATGACTTCC AAGCTGGCCGTGGCT-3' and reverse, 5'-TCTCAGCCC TCTTCAAAAACTTCTC-3'); and GAPDH forward, 5'-ACC ACAGTTCATGCCATCAC-3' and reverse, 5'-TCCACCACC 

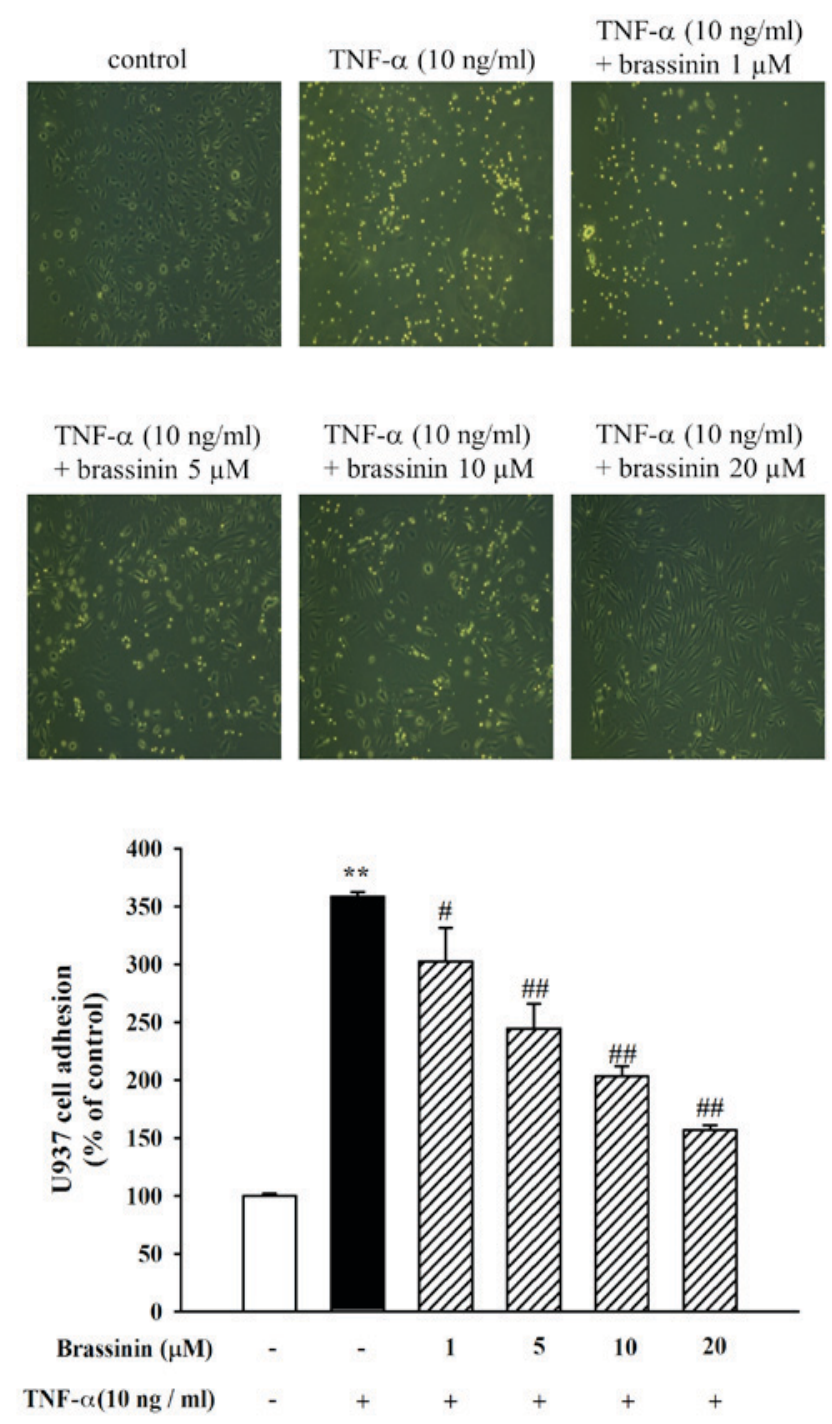

Figure 2. Effect of brassinin on adhesion of monocytes to TNF- $\alpha$-stimulated HUVECs. HUVECs were pretreated with brassinin for $30 \mathrm{~min}$ and the stimulated with TNF- $\alpha(10 \mathrm{ng} / \mathrm{ml})$ for $6 \mathrm{~h}$. The amounts of adherent U937 cells were visualized by fluorescence microscopy and quantified by spectrofluorometry. Values are expressed as mean \pm standard error of the mean. ${ }^{* *} \mathrm{P}<0.01$ vs. control; ${ }^{\#} \mathrm{P}<0.05$ and ${ }^{\# \#} \mathrm{P}<0.01$ vs. TNF- $\alpha$ alone. TNF, tumor necrosis factor; HUVECs, human umbilical vein endothelial cells.

CTGTTGCTGTA-3'. The thermocycling conditions were as follows: an initial step at $94^{\circ} \mathrm{C}$ for $15 \mathrm{~min}$, followed by 45 cycles of $94^{\circ} \mathrm{C}$ for $20 \mathrm{sec}, 60^{\circ} \mathrm{C}$ for $20 \mathrm{sec}$ and $72^{\circ} \mathrm{C}$ for $30 \mathrm{sec}$, and a final extension step of $72^{\circ} \mathrm{C}$ for $5 \mathrm{~min}$. The PCR products were subjected to $1 \%$ agarose gel electrophoresis, and then detected on a ChemiDoc imaging system (Bio-Rad Laboratories, Inc.).

Preparation of cytoplasmic and nuclear extracts. Nuclear and cytoplasmic extracts were prepared on ice, as previously described by Mackman et al (16). Cells were harvested and washed with $1 \mathrm{ml}$ buffer A (10 mM HEPES pH 7.9, $1.5 \mathrm{mM}$ $\mathrm{MgCl}_{2}$, and $19 \mathrm{mM} \mathrm{KCl}$ ) for $5 \mathrm{~min}$ at $600 \mathrm{x} \mathrm{g}$. The cells were resuspended in buffer A and 0.1\% NP40, left for $10 \mathrm{~min}$ on ice to lyse and then centrifuged at $600 \mathrm{x} \mathrm{g}$ for $3 \mathrm{~min}$. The supernatant was saved as cytosolic extract. The nuclear pellet was then washed in $1 \mathrm{ml}$ buffer $\mathrm{A}$ at 4,200 $\mathrm{x}$ g for $3 \mathrm{~min}$, re-suspended in $30 \mu \mathrm{l}$ buffer $\mathrm{C}$ (20 mM HEPES pH 7.9, 25\% glycerol, $0.42 \mathrm{M} \mathrm{NaCl}, 1.5 \mathrm{mM} \mathrm{MgCl}$, and $0.2 \mathrm{mM}$ EDTA), rotated for $30 \mathrm{~min}$ at $4^{\circ} \mathrm{C}$, then centrifuged at $14,300 \mathrm{x} \mathrm{g}$ for $20 \mathrm{~min}$. The supernatant was used as nuclear extract.

Intracellular ROS production assay. The fluorescent probe chloromethyl-2',7'-dichlorodihydrofluorescein diacetate (CM- $\mathrm{H}_{2}$ DCFDA; Thermo Fisher Scientific, Inc.) was used to determine the intracellular generation of ROS. Briefly, confluent HUVECs in $60 \mathrm{~mm}^{2}$ dish culture plates were pretreated with brassinin for $30 \mathrm{~min}$, then stimulated with TNF- $\alpha$ for $6 \mathrm{~h}$. Cells were then incubated with $20 \mu \mathrm{M}$ CM- $\mathrm{H}_{2}$ DCFDA for $1 \mathrm{~h}$. The resulting fluorescence intensity was measured using a spectrofluorometer (Infinite F200 Pro; Tecan Group Ltd.) at excitation and emission wavelengths of 485 and $535 \mathrm{~nm}$, respectively.

Statistical analysis. Results were expressed as the mean \pm standard error of the mean of at least three independent experiments. Significance was analyzed with one-way analysis of variance followed by a Dunnett's test, using SigmaPlot version 10.0 (Systat Software, Inc., San Jose, CA, USA). P $<0.05$ was considered to indicate a statistically significant difference.

\section{Results}

Effect of brassinin on TNF- $\alpha$-induced adhesion of U937 cells to HUVECs. To confirm the inhibitory effect of brassinin on the HUVEC-monocyte interaction, a cell adhesion assay was performed between U937 cells and TNF- $\alpha$-stimulated HUVECs. HUVECs were pretreated with different concentrations of brassinin $(1-20 \mu \mathrm{M})$ and then stimulated with TNF- $\alpha(10 \mathrm{ng} / \mathrm{ml})$ for $6 \mathrm{~h}$. U937 cells were allowed to adhere to the treated HUVECs and then quantified. As illustrated in Fig. 2, control HUVECs exhibited minimal binding to U937 cells without TNF- $\alpha$ stimulation. However, adhesion of U937 cells to the HUVECs was dramatically increased following TNF- $\alpha$ stimulation (Fig. 2). By contrast, pretreatment with brassinin inhibited the adhesion of U937 cells to TNF- $\alpha$-induced HUVECs (Fig. 2). Thus, brassinin may be effective towards preventing the early process of monocyte adhesion to the vascular endothelium in vascular inflammation.

Effect of brassinin on inflammation-related factors in TNF- $\alpha$-induced HUVECs. Western blot analysis was performed to confirm the effect of brassinin on the expression of cell adhesion molecules in HUVECs. Exposure to TNF- $\alpha$ for $6 \mathrm{~h}$ resulted in a significantly pronounced expression of VCAM-1, ICAM-1 and E-selectin in HUVECs, compared with control untreated cells (Fig. 3A). Pretreatment with brassinin, however, significantly inhibited the TNF- $\alpha$-induced VCAM-1, ICAM-1 and E-selectin protein expression levels (Fig. 3A). Expression of the adhesion molecules in the cell surface of the HUVECs was also examined by ELISA. Consistent with the results from the western blotting, expression of VCAM-1, ICAM-1 and E-selectin on the cell surface of HUVECs was significantly increased by TNF- $\alpha$ stimulation (Fig. 3B). However, TNF- $\alpha$-induced cell surface protein expression was suppressed by brassinin pretreatment in a dose-dependent manner (Fig. 3B). 
A
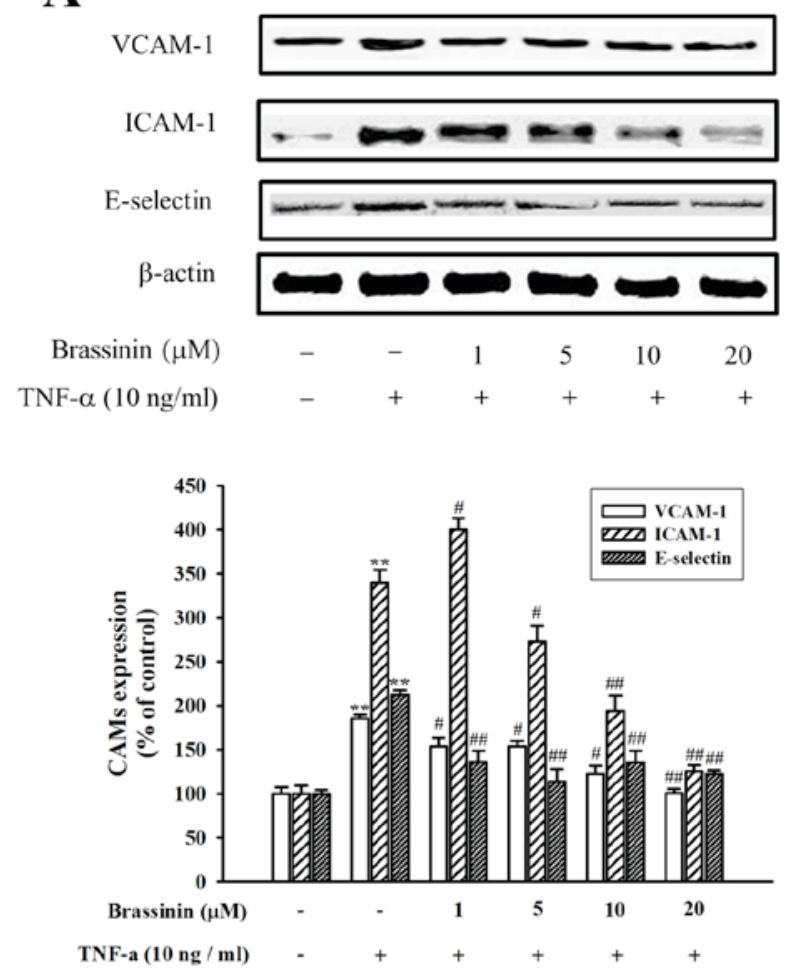

B

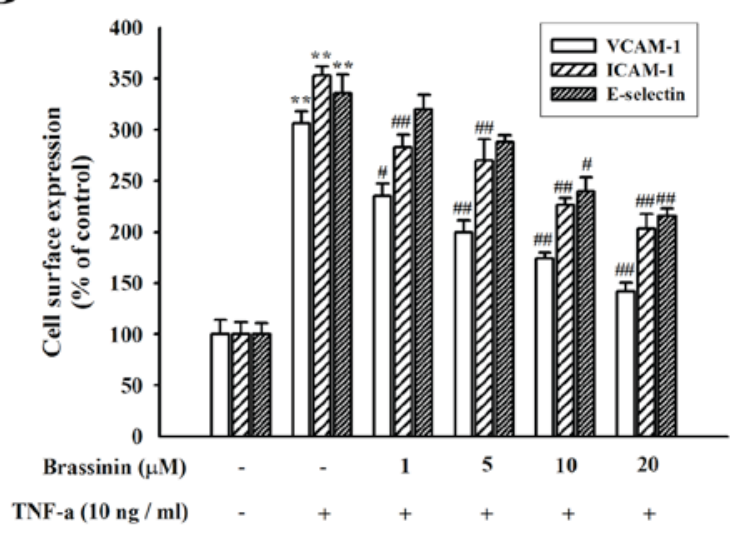

Figure 3. Effect of brassinin on inflammation-related factors in TNF- $\alpha$-induced HUVECs. HUVECs were pretreated with brassinin for $30 \mathrm{~min}$ and then stimulated with TNF- $\alpha(10 \mathrm{ng} / \mathrm{ml})$ for $6 \mathrm{~h}$. (A) VCAM- 1 , ICAM-1 and E-selectin protein expression levels were analyzed in total cell extracts by western blotting. (B) Cell surface expression of VCAM-1, ICAM-1 and E-selectin was measured by ELISA. ${ }^{* *} \mathrm{P}<0.01$ vs. control; ${ }^{*} \mathrm{P}<0.05$ and ${ }^{\# \#} \mathrm{P}<0.01$ vs. TNF- $\alpha$ alone. TNF, tumor necrosis factor; HUVECs, human umbilical vein endothelial cells; VCAM-1, vascular cell adhesion molecule-1; ICAM-1, intracellular adhesion molecule-1; E-selectin, endothelial-selectin.

Effect of brassinin on TNF- $\alpha$-induced translocation and expression of $N F-\kappa B$ p 65 . NF- $\mathrm{kB}$ is activated upon cytokine stimulation via phosphorylation and degradation of its inhibitor, IкB- $\alpha$. Activation of NF- $\kappa \mathrm{B}$ requires translocation from the cytoplasm to the nucleus, and this translocation results in transcription initiation for genes associated with cellular growth (8). Therefore, the effect of brassinin on NF-kB activation and translocation was examined. By western blot analysis,
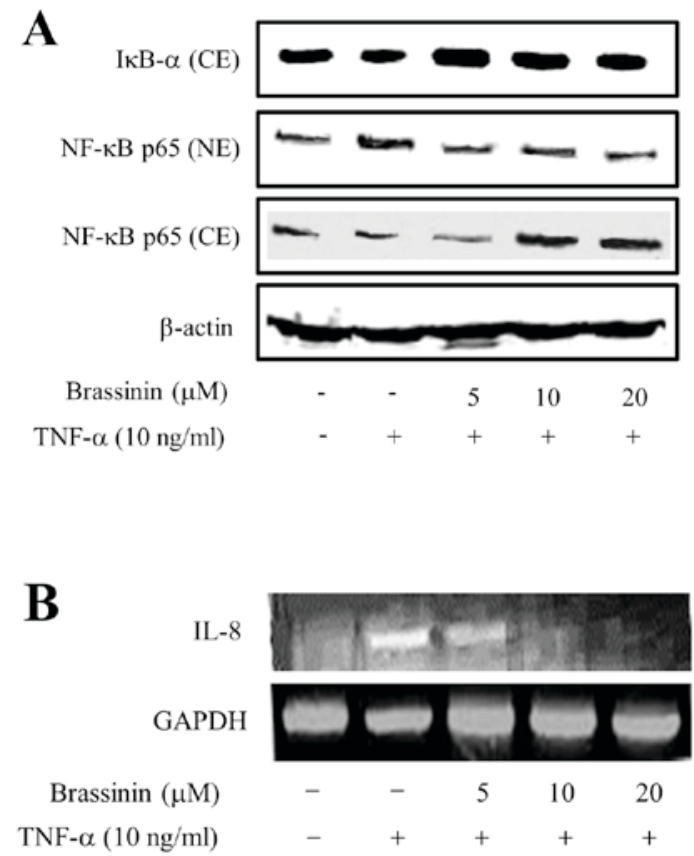

Figure 4. Effect of brassinin on TNF- $\alpha$-induced translocation and expression of NF- $\kappa \mathrm{B}$ p 65 . HUVECs were pretreated with brassinin $(5-20 \mu \mathrm{M})$ for $30 \mathrm{~min}$ and then stimulated with TNF- $\alpha(10 \mathrm{ng} / \mathrm{ml})$ for $6 \mathrm{~h}$. (A) The NE and CE protein extracts were prepared, separated on $10 \%$ SDS-PAGE and immunoblotted with antibodies specific for $\mathrm{I} \kappa \mathrm{B}-\alpha$ and NF- $\kappa \mathrm{B}$ p 65 . $\beta$-actin was used as a loading control. (B) IL- 8 mRNA expression levels were analyzed by reverse transcription-polymerase chain reaction. GAPDH was used as an internal control. TNF, tumor necrosis factor; NF, nuclear factor; HUVECs, human umbilical vein endothelial cells; I $\mathrm{B}$, inhibitor of $\kappa \mathrm{B}$; IL, interleukin; $\mathrm{CE}$, cytoplasmic extract; NE, nuclear extract.

I $\mathrm{B}-\alpha$ expression levels in the cytoplasm were increased following pretreatment with brassinin of TNF- $\alpha$-induced HUVECs (Fig. 4A). In addition, western blot analysis revealed that the levels of NF- $\mathrm{KB}$ p65 in the cytoplasm decreased, while its levels in the nucleus increased following pretreatment with brassinin, compared with cells treated with TNF- $\alpha$ alone (Fig. 4A). To confirm whether brassinin has an inhibitory effect on chemokines such as IL-8, that is associated with human atheroma, RT-PCR analysis was performed in the presence or absence of TNF- $\alpha$ and/or brassinin. As illustrated in Fig. 4B, TNF- $\alpha$ stimulation obviously increased the mRNA expression levels of IL-8 compared with untreated cells, whereas pretreatment with brassinin markedly abrogated this TNF- $\alpha$-induced IL- 8 mRNA expression in a dose-dependent manner.

Antioxidant effect of brassinin on TNF- $\alpha$-induced ROS production. To confirm whether brassinin has an inhibitory effect on TNF- $\alpha$-induced oxidative stress, ROS levels in HUVECs were detected using the $\mathrm{CM}-\mathrm{H}_{2}$ DCFDA probe and spectrofluorometry. As illustrated in Fig. 5, intracellular ROS levels were increased following TNF- $\alpha$ stimulation in HUVECs, compared with untreated control cells. However, pretreatment with brassinin significantly decreased the TNF- $\alpha$-induced ROS levels (Fig. 5). In addition, NAC $(10 \mathrm{mM})$ was used as a positive control to confirm the inhibitory effect of brassinin. 


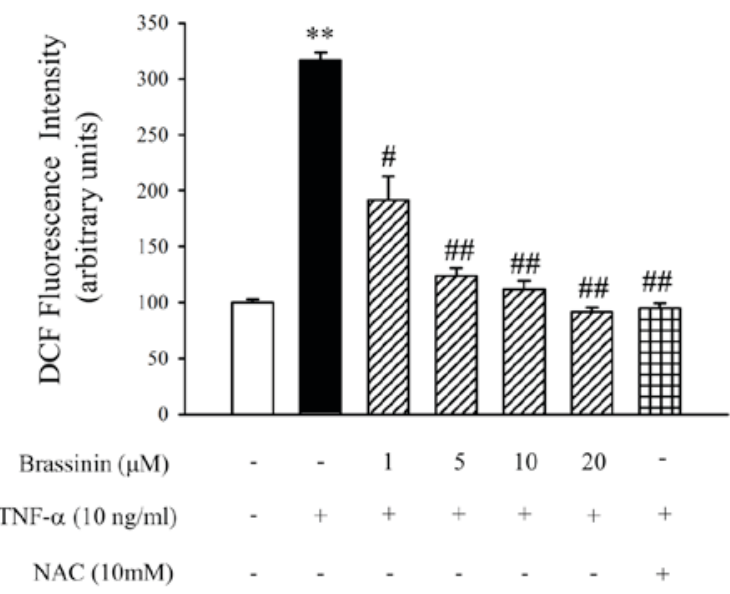

Figure 5. Effect of brassinin on TNF- $\alpha$-induced ROS production in HUVECs. Cells were pretreated with brassinin $(5-20 \mu \mathrm{M})$ for $30 \mathrm{~min}$ and then stimulated with TNF- $\alpha(10 \mathrm{ng} / \mathrm{ml})$ for $6 \mathrm{~h}$. The ROS probe CM- $\mathrm{H}_{2}$ DCFDA $(20 \mathrm{mM})$ was then added for $30 \mathrm{~min}$, and the resulting DCF fluorescence was measured by spectrofluorometry. NAC $(10 \mathrm{mM})$ was used as a positive control to confirm the inhibitory effect of brassinin. ${ }^{* *} \mathrm{P}<0.01 \mathrm{vs}$. control; ${ }^{*} \mathrm{P}<0.05$ and ${ }^{\# \#} \mathrm{P}<0.01 \mathrm{vs}$. TNF- $\alpha$ alone. TNF, tumor necrosis factor; ROS, reactive oxygen species; HUVECs, human umbilical vein endothelial cells; CM- $\mathrm{H}_{2}$ DCFD, chloromethyl-2',7'-dichlorodihydrofluorescein diacetate; DCF, dichlorofluorescein; NAC, $\mathrm{N}$-acetylcysteine.

\section{Discussion}

The present study provides the first evidence suggesting that brassinin inhibits vascular inflammation via inhibition of TNF- $\alpha$-induced adhesion molecules, NF- $\kappa B$ activation, and ROS production in HUVECs.

The initiation step of vascular inflammation is associated with the pathogenesis of atherosclerosis. Several previous studies have focused on the importance of adhesion molecules in atherosclerosis. This initiation step is mediated by the interaction between monocytes and the molecules expressed on the endothelial cells surface (17). The expression of these CAMs on the endothelial cell membrane increases significantly when they are stimulated with endotoxin, IL-1 and TNF- $\alpha$ (18). TNF- $\alpha$ is a very important mediator of the inflammatory pathway, and TNF- $\alpha$ is closely associated with the pathogenesis of many cardiovascular diseases, including atherosclerosis (19). Therefore, the present study investigated whether brassinin may attenuate the expression of VCAM-1, ICAM-1 and E-selectin, and monocyte adhesion to TNF- $\alpha$-stimulated HUVECs. The results suggested that brassinin exhibited an inhibitory effect to prevent the TNF- $\alpha$-induced vascular inflammatory process in endothelial cells.

$\mathrm{NF}-\mathrm{\kappa B}$ is an important transcription factor that activates expression of many inflammatory genes (20). Expression of NF- $\mathrm{\kappa B}$ is induced in inflammatory vascular diseases. In unstimulated cells, NF- $\mathrm{\kappa B}$ exists in the cytosol as a heterodimer composed of the p50 and p65 subunits, and bound to the inhibitory protein I $\kappa \mathrm{B}-\alpha$. When cells are stimulated, I $\mathrm{B}-\alpha$ is phosphorylated and degraded, allowing NF- $\kappa \mathrm{B}$ to translocate to the nucleus and to start gene transcription (21). To confirm whether brassinin exhibits its anti-inflammatory effect on TNF- $\alpha$-stimulated endothelial cells through the
NF- $\kappa B$ pathway, protein expression of NF- $\kappa B$ and I $\mathrm{KB}-\alpha$ was examined in the cytosol and the nucleus by western blotting. The results demonstrated that brassinin significantly suppressed TNF- $\alpha$-induced accumulation of NF- $\kappa B$ p65 protein in the nucleus, suggesting that brassinin attenuated $\mathrm{NF}-\mathrm{\kappa B}$ p65 nuclear translocation. Increased expression of IL-8 has been reported in atherosclerotic lesions and circulating macrophages from patients with atherosclerosis (22). In addition, IL-8 serves a key role in the initiation step of inflammation by enhancing the adhesion of monocytes to the vascular endothelium (5). In the present study, brassinin treatment suppressed the mRNA expression levels of IL-8 in TNF- $\alpha$-induced HUVECs. These results indicated that brassinin may have an inhibitory effect on inflammation of vascular endothelial cells. In vascular inflammation, oxidative stress is crucial in the initiation step of atherosclerosis, and signifies vascular disorder. ROS is essential to the normal function of cells, but adequate levels of antioxidant defenses are required in order to avoid the harmful effects of excessive ROS production (23). The ROS/NF- $\kappa$ B pathway is recognized as a key mediator involved in the regulation of inflammatory responses in vascular diseases (7). Therefore, the production of ROS in HUVECs was examined in the present study, using the $\mathrm{CM}-\mathrm{H}_{2} \mathrm{DCFDA}$ probe and fluorescence microscopy. The results demonstrated that, in cells that were pretreated with brassinin, TNF- $\alpha$-induced intracellular ROS production was significantly decreased.

In conclusion, the present study suggested that brassinin could have a protective effect on the vascular inflammation process, by inhibiting the expression of adhesion molecules and the activation of the ROS/NF- $\mathrm{BB}$ pathway in HUVECs. Therefore, these results provide evidence that brassinin may be beneficial in the future for the prevention and treatment of atherosclerosis.

\section{Acknowledgements}

The present work was supported by the National Research Foundation of Korea funded by the Ministry of Science, ICT and Future Planning of Korea (grant no. 2008-0062484).

\section{References}

1. Lee YJ, Moon MK, Hwang SM, Yoon JJ, Lee SM, Seo KS, Kim JS, Kang DG and Lee HS: Anti-Inflammatory effect of Buddleja officinalis on vascular inflammation in human umbilical vein endothelial cells. Am J Chin Med 38: 585-598, 2010.

2. Liu X, Pan L, Wang X, Gong Q and Zhu YZ: Leonurine protects against tumor necrosis factor- $\alpha$-mediated inflammation in human umbilical vein endothelial cells. Atherosclerosis 222: 34-42, 2012.

3. Ross EA, Douglas MR, Wong SH, Ross EJ, Curnow SJ, Nash GB, Rainger E, Scheel-Toellner D, Lord JM, Salmon M and Buckley CD: Interaction between integrin alpha9beta1 and vascular cell adhesion molecule-1 (VCAM-1) inhibits neutrophil apoptosis. Blood 107: 1178-1183, 2006.

4. Sana TR, Janatpour MJ, Sathe M, McEvoy LM and McClanahan TK: Microarray analysis of primary endothelial cells challenged with different inflammatory and immune cytokines. Cytokines 29: 256-269, 2005.

5. Gerszten RE, Garcia-Zepeda EA, Lim YC, Yoshida M, Ding HA, Gimbrone MA Jr, Luster AD, Luscinskas FW and Rosenzweig A: MCP-1 and IL-8 trigger firm adhesion of monocytes to vascular endothelium under flow conditions. Nature 398: 718-723, 1999. 
6. Tak PP, Gerlag DM, Aupperle KR, van de Geest DA, Overbeek M, Bennett BL, Boyle DL, Manning AM and Firestein GS: Inhibitor of nuclear factor kappaB kinase beta is a key regulator of synovial inflammation. Arthritis Rheum 44: 1897-1907, 2001.

7. Chen JW, Chen YH, Lin FY, Chen YL and Lin SJ: Ginkgo biloba extract inhibits tumor necrosis factor-alpha-induced reactive oxygen species generation, transcription factor activation, and cell adhesion molecule expression in human aortic endothelal cells. Arterioscler Thromb Vasc Biol 23: 1559-1566, 2003.

8. Iademarco MF, Mcquillan JJ, Rosen GD and Dean DC: Characterization of the promoter for vascular cell adhesion molecule-1 (VCAM-1). J Biol Chem 267: 16323-16329, 1992.

9. Gloire G, Legrand-Poels S and Piette J: NF-kappaB activation by reactive oxygen species: Fifteen years later. Biochem Pharmacol 72: 1493-1505, 2006.

10. Lee SM,Lee YJ,Kim YC, Kim JS, Kang DG and Lee HS: Vascular protective role of vitexicarpin isolated from Vitex rotundifolia in human umbilical vein endothelial cells. Inflammation 35 : 584-593, 2012

11. Kumar S, Sharma A, Madan B, Singhal V and Ghosh B Isoliquiritigenin inhibits IKappaB kinase activity and ROS generation to block TNF-alpha induced expression of cell adhesion molecules on human endothelial cells. Biochem Pharmacol 73: 1602-1612, 2007.

12. Kim SM, Oh EY, Lee JH, Nam DW, Lee SG, Lee JH, Kim SH, Shin BS and Ahn KS: Brassinin combined with capsaicin enhances apoptotic and anti-metastatic effects in PC-3 human prostate cancer cells. Phytother Res 29: 1828-1836, 2015.

13. Banerjee T, DuHadaway JB, Gaspari P, Sutanto-Ward E, Munn DH, Mellor AL, Malachowski WP, Prendergast GC and Muller AJ: A key in vivo antitumor mechanism of action of natural product-based brassinins is inhibition of indoleamine 2,3-dioxygenase. Oncogene 27: 2851-2857, 2008.

14. Kello M, Drutovic D, Chripkova M, Pilatova M, Budovska M, Kulikova L, Urdzik P and Mojzis J: Ros-dependent antiproliferative effect of brassinin derivative hombrassinin in human colorectal cancer Caco2 cells. Molecules 19: 10877-10897, 2014.
15. Schneider CA, Rasband WS and Eliceiri KW: NIH Image to Image J: 25 years of image analysis. Nat Methods 9: 671-675, 2012.

16. Mackman N, Brand K and Edgington TS: Lipopolysaccharide mediated transcriptional activation of the human tissue factor gene in THP-1 cells requires both activator protein-1 and nuclear factor kappa B binding sites. J Exp Med 174: 1517-1526, 1991.

17. Bourdillon MC, Poston RN, Covacho C, Chignier E, Bricca G and McGregor JL: ICAM-1 deficiency reduces atherosclerotic lesions in double-knockout mice (ApoE(-/-)/ICAM-1(-/-)) fed a fat or a chow diet. Arterioscler Thromb Vasc Biol 20: 2630-2635, 2000.

18. Dustin ML, Rothlein R, Bhan AK, Dinarello CA and Springer TA: Induction by IL 1 and interferion-gamma: Tissue distribution, biochemistry, and function of a natural adherence molecule (ICAM-1). J Immunol 137: 245-254, 1986.

19. Bradley JR: TNF-mediated inflammatory disease. J Pathol 214: 149-160, 2008

20. Hattori Y, Kasai K and Gross SS: NO suppresses while peroxynitrite sustains NF-kappaB: A paradigm to rationalize cytoprotective and cytotoxic actions attributed to NO. Cardiovase Res 63: 31-40, 2004.

21. Brasier AR: The nuclear factor-kappaB-interleukin-6 signalling pathway mediating vascular inflammation. Cardiovasc Res 86: 211-218, 2010.

22. Simonini A, Moscucci M, Muller DW, Bates ER, Pagani FD, Burdick MD and Strieter RM: IL-8 is an angiogenic factor in human coronary atherectomy tissue. Circulation 101: 1519-1526, 2000.

23. Victor VM, Rocha M, Solá E, Bañuls C, Garcia-Malpartida K and Hernández-Mijares A: Oxidative stress, endothelial dysfunction and atherosclerosis. Curr Pharm Des 15: 2988-3002, 2009. 